\title{
Các nhân tố ảnh hưởng đến vượt dụ̣ toán trong các dự án xây dụng hạ tầng kỹ thuật tại thành phố Hồ Chí Minh
}

\section{Factors affecting cost overrun of infrastructure projects in Ho Chi Minh City}

\author{
Trần Phạm Khánh Toàn ${ }^{1,2^{*}}$ \\ ${ }^{1}$ Ủy ban nhân dân Quận 10, Thành phố Hồ Chí Minh, Việt Nam \\ ${ }^{2}$ Trường Đai học Mở Thành phố Hồ Chí Minh, Việt Nam \\ *Tác giả liên hệ, Email: khanhtoan014@gmail.com
}

THÔNG TIN

DOI: $10.46223 / \mathrm{HCMCOUJS}$. econ.vi.16.3.1979.2021

Ngày nhận: 05/08/2020

Ngày nhận lại: 09/12/2020

Duyệt đăng: 25/02/2021

Tù khóa:

dự án; hạ tầng kỹ thuật; Thành phố Hồ Chí Minh; vượt dự toán

\section{TÓM TÁT}

Các dự án hạ tầng kỹ thuật đóng vai trò rất quan trọng trong việc phát triển kinh tế - xã hội. Tuy nhiên, có một thực tế là các dự án này thường vượt dự toán. Bài viết này chỉ ra các nhân tố cũng như xem xét tác động của các nhân tố đến việc vượt dự toán trong các dự án xây dựng hạ tầng kỹ thuật tại Thành phố Hồ Chí Minh. Thông qua việc sử dụng phép phân tích nhân tố và hồi quy cho dữ liệu thu thập từ 184 cán bộ, công chức, các kỹ sư, chuyên viên đang tham gia thi công, xây dựng, giám sát công trình hạ tầng kỹ thuật trên địa bàn Thành phố, kết quả cho thấy cho thấy sáu nhân tố gây vượt dự toán tại các dự án, được xếp theo thứ tự tăng dần, bao gồm: Chính sách; Môi trường tự nhiên - xã hội; Kinh tế; Tư vấn; Nhà thầu; Chủ đầu tư. Ngoài ra, bài viết cũng không tìm thấy sự khác biệt trong việc đánh giá vượt dự toán của những người có kinh nghiệm khác nhau và tham gia các loại hình dự án khác nhau.

\section{ABSTRACT}

This article identifies the factors as well as examines the impact of these factors on cost overrun in infrastructure construction projects in Ho Chi Minh City. Data was collected from 184 officials, civil servants, engineers who are participating in the construction. Using the method of testing the reliability of scale (Cronbach's Alpha), exploratory factors analysis, and multivariate regression analysis, the results show that six factors that are causing cost overrun in an increasing order include: (1) Policies; (2) Natural and social condition; (3) Economic situations; (4) Advisory's capability; (5) Contractors' capability; (6) Project leadership skills and experience. In addition, the study found no difference in the estimation cost overrun in the projects of people with different experiences and involved in various types of projects. project; infrastructure; Ho Chi Minh City; cost overrun 


\section{Giới thiệu}

Các dự án hạ tầng kỹ thuật được xem là "xương sống” cho sự phát triển kinh tế, xã hội, góp phần nâng cao chất lượng cuộc sống của người dân (Prasad, Vasugi, Venkatesan, \& Bhat, 2019) do đó chính phủ các quốc gia đều tập trung các nguồn vốn đầu tư cho các dự án hạ tầng kỹ thuật (Andric, Mahamadu, Wang, Zou, \& Zhong, 2019). Các dự án xây dựng hạ tầng kỹ thuật là một phần trong các dự án xây dựng cơ bản, bao gồm các dự án xây dựng hệ thống công trình giao thông, bến cảng, sân bay, hệ thống cấp thoát nước, hệ thống điện chiếu sáng, các công trình bảo vệ môi trường và các công trình phụ trợ khác, ...

Đi cùng với tốc độ phát triển kinh tế ngày càng cao thì Thành phố Hồ Chí Minh có nhu cầu rất lớn về phát triển hạ tầng kỹ thuật, bên cạnh việc hoàn thành các dự án đúng hạn thì một trong những mục tiêu quan trọng của quản lý dự án là đảm bảo các nguồn vốn đầu tư cho dự án được quản lý chặt chẽ, sử dụng một cách hiệu quả, đảm bảo các dự án không vượt dự toán. Điều này rất có ý nghĩa trong bối cảnh nguồn vốn đầu tư từ ngân sách nhà nước hạn hẹp, nguồn vốn ODA chậm lại, còn nguồn vốn từ doanh nghiệp thì hạn chế. Thực trạng hiện nay ở Thành phố Hồ Chí Minh nhiều dự án hạ tầng kỹ thuật đã được Ửy ban nhân dân Thành phố có quyết định điều chỉnh dự toán ban đầu như dự án mở rộng đường Tô Ký, Dự án nối đường Võ Văn Kiệt với cao tốc Thành phô Hồ Chí Minh - Trung Lương, dự án hầm chui Ngã Tư An Sương, ...

Hiện nay, vấn đề vượt dự toán tại các dự án xây dựng đã thu hút được nhiều sự quan tâm của các nhà nghiên cứu trên thế giới tuy nhiên chưa có nghiên cứu cụ thể nào về các nhân tố gây vượt dự toán tại các công trình hạ tầng kỹ thuật tại Thành phố Hồ Chí Minh. Đặc biệt là việc nguồn vốn dành cho các công trình hạ tầng kỹ thuật được lấy từ vốn ngân sách nhà nước, vốn ODA, vốn tài trợ nước ngoài, vốn do nhà nước bảo lãnh, ... cần phải được quản lý chặt chẽ, tiết kiệm tránh tình trạng thất thoát, lãng phí. Vì vậy, việc đi sâu nghiên cứu và tìm ra các nhân tố gây vượt dự toán tại các dự án này là hết sức cần thiết vì loại hình đầu tư xây dựng này có rất nhiều điểm khác biệt so với dự án công trình dân dụng như: tổng mức đầu tư lớn, phụ thuộc nhiều vào quy định pháp luật; các điều kiện về tự nhiên, địa chất, phục vụ nhu cầu thiết yếu của đời sống người dân. Do vậy, mục tiêu của nghiên cứu này chỉ ra các nhân tố và đánh giá mức độ tác động của từng nhân tố gây vượt dự toán tại các dự án hạ tầng kỹ thuật tại Thành phố Hồ Chí Minh; trên cơ sở đó để đưa ra các khuyến nghị, nhằm hạn chế vượt dự toán tại các công trình này.

\section{Cơ sở lý thuyết và mô hình nghiên cứu}

\subsection{Co' sở lý thuyết}

Trong nghiên cứu này, vượt dự toán được hiểu là khi chi phí cuối cùng của dự án vượt so với ước tính ban đầu (Alinaitwe, Apolot, \& Tindiwensi, 2013). Enshassi, Mohamed, và Abushaban (2009) cho rằng vượt dự toán là sự khác biệt/sự chênh lệch giữa chi phí dự toán ban đầu trong hợp đồng cho một dự án cụ thể và chi phí thực tế sau khi hoàn thành dự án đó. Khi chi phí xây dựng vượt tầm kiểm soát sẽ gây áp lực đầu tư, tăng chi phí xây dựng, tác động đến ra quyết định đầu tư, gây lãng phí ngân sách nhà nước và có thể dẫn đến các hành vi vi phạm pháp luật (Ali \& Kamaruzzaman, 2010).

Theo Báo cáo cơ sở hạ tầng tại Ấn Độ, Datta (2002) cho rằng một vấn đề thường gặp trong các dự án đầu tư công đó là việc chi phí leo thang; đồng thời, tồn tại mối quan hệ giữa kế hoạch thi công, phạm vi công việc và điều kiện dự án. Bất kì sự thay đổi nào trong các yếu tố này sẽ ảnh hưởng đến ngân sách và thời gian hoàn thành. Điều này đã cung cấp một cái nhìn khái quát về những nguyên nhân dẫn đến sự chậm tiến độ và vượt dự toán (Khalil \& Ghafly, 1999). Các nhân tố gây nên vượt dự toán có thể được phân chia thành các nhân tố bên trong và bên ngoài. Theo đó, các yếu tố về kinh tế, chính sách quản lý, pháp luật và các yếu tố bên trong là sự yếu kém về năng lực quản lý dự án, trong đó tập trung là việc thẩm định dự án, thiết kế, thay đổi phạm vi; thi công và thay đổi các yêu cầu (Love, Smith, Simpson, Regan, \& Olatunji, 2015). 
Tại Việt Nam, Nguyen (2009) cho rằng ngành xây dựng là trụ cột của nền kinh tế quốc dân và một vấn đề cần phải lưu ý trong suốt quá trình thực hiện dự án đầu tư là vượt dự toán. Vấn đề này tác động xấu đến hiệu quả dự án và gây thiệt hại quyền lợi cho các bên liên quan. Do đó, các nhà quản lý dự án xây dựng cần phải quan tâm đến chi phí và thời gian. Tuy nhiên, tùy thuộc vào từng loại dự án, mức độ, quy mô, phạm vi khác nhau mà sẽ có các nhân tố liên quan gây chậm trễ và vượt dự toán khác nhau. Cao và Swierczek (2010) cho thấy vấn đề vượt dự toán có nguồn gốc từ những người lo sợ mất quyền lực liên quan đến đơn vị quản lý dự án. Quá trình thực hiện dự án bị ảnh hưởng bởi tính thiếu minh bạch trong đấu thầu, quá nhiều quy định và hạn chế trong việc thực thi các biện pháp phòng ngừa tham nhũng, lãng phí.

\subsection{Tổng quan các nghiên cứu trước}

Olawale và Sun (2010) đã tìm hiểu việc kiểm soát chi phí và thời gian của các dự án xây dựng và phát hiện ra rằng nguyên nhân chính của việc chậm tiến độ và vượt dự toán bao gồm việc thay đổi thiết kế, rủi ro/không chắc chắn, đánh giá dự án không chính xác, sự phức tạp của dự án và năng lực của nhà thầu. Bari, Yusuff, Ismail, Jaapar, và Ahmad (2012) phân tích các nhân tố ảnh hưởng đến chi phí xây dựng các dự án hệ thống xây dựng công nghiệp và phát hiện ra các yếu tố quan trọng nhất ảnh hưởng đến chi phí xây dựng dự án gồm các đặc điểm của dự án, thuộc tính nhà thầu và điều kiện thị trường.

Sau khi thống kê 169 dự án tại Palestine từ năm 2004 đến năm 2008, Magamid và Bruland (2012) nhận thấy rằng 1400\% các dự án đều bị lệch dự toán. Độ lệch giữa chi phí dự đoán và thực tế bình quân $14.6 \%$ dao động từ $-39 \%$ đến $98 \%$.

Subramani, Sruthi, và Kavitha (2014) phân tích chi phí xây dựng ở Ấn Độ và phát hiện ra rằng quyết định chậm chạp, quản lý yếu kém, nguyên vật liệu tăng giá, rủi ro trong thi công và những vấn đề phát sinh trong việc thu hồi đất, giải phóng mặt bằng là nguyên chính của vượt dự toán. Nghiên cứu của Honrao và Desai (2015) chỉ ra 05 nhóm nguyên nhân chính gồm Nhà thầu, Chủ đầu tư, Tư vấn, Dịch vụ tiện ích công cộng, Chính sách nhà nước là nguyên nhân gây chậm trễ làm vượt dự toán các dự án xây dựng hạ tầng kỹ thuật ở Ấn Độ.

Durdyev, Omarov, Ismail, và Lim (2017) đã kiểm tra các yếu tố gây vượt chi phí ở Campuchia và phát hiện ra rằng quản lý dự án và chi phí, tài chính dự án cũng như các yếu tố rủi ro dự án là chính các yếu tố quyết định của chi phí vượt mức. Johnson và Babu (2020) đã xem xét chi phí vượt mức ở UAE ngành xây dựng và lưu ý rằng các yếu tố vượt chi phí chính là sự thay đổi thiết kế, ước tính chi phí kém, sự chậm trễ trong quá trình ra quyết định của khách hàng, hạn chế tài chính của khách hàng và phương thức mua sắm không phù hợp.

Ilyas, Li, và Ulah (2019) tìm hiểu việc chậm tiến độ và vượt dự toán các công trình xây dựng tại Pakistan. Với 200 bảng câu hỏi được phân phát cho các chuyên gia, kỹ sư xây dựng tại công trường, công ty xây dựng. Nghiên cứu đã cho thấy quản lý công trình yếu kém, lực lượng nhân công, mức độ phức tạp của công trình và thiếu hụt nguyên vật liệu là nguyên nhân chính dẫn đến việc chậm tiến độ và vượt dự toán tại các dự án.

Prasad và cộng sự (2019) đã phân tích các yếu tố vượt chi phí ở Ấn Độ và kết luận sự chậm trễ trong thanh toán cho công việc làm thêm, sự chậm trễ trong yêu cầu giải quyết của chủ sở hữu, nhà thầu, khó khăn tài chính và thanh toán trễ từ các nhà thầu cho các nhà thầu phụ là chính yếu tố vượt chi phí.

Tại Việt Nam, Le, Lee, và Lee (2008) trong báo cáo nghiên cứu về "Chậm trễ và vượt dự toán trong các dự án lớn ở Việt Nam: So sánh với một số nước khác” khảo sát 21 nhân tố và tìm thấy ba nguyên nhân hàng đầu dẫn đến vượt dự toán trong các dự án lớn ở Việt Nam là: giá nguyên vật liệu đầu vào tăng do lạm phát, khối lượng vật tư không chính xác và chi phí lao động 
tăng do hạn chế về môi trường.

Nguyen (2009) thực hiện phân tích 216 dự án xây dựng tại Thành phố Hồ Chí Minh phát hiện 06 nhân tố ảnh hưởng đến biến động chi phí dự án: Năng lực bên thực hiện; Năng lực bên hoạch định; Sự gian lận và thất thoát; Môi trường kinh tế; Chính sách và môi trường tự nhiên.

Trinh (2014) đã thực hiện một cuộc khảo sát các dự án xây dựng công trình giao thông ở các Ban quản lý, các Sở của các tỉnh phía Nam và các công ty tham gia thi công, tư vấn. Kết quả nghiên cứu đã chỉ ra rằng khó khăn tài chính và cung cấp nguyên liệu chậm là yếu tố ảnh hưởng nhiều nhất đến dự án vượt dự toán. Tiếp theo là do những hạn chế trong năng lực của Nhà thầu thi công.

\section{Kết quả nghiên cứu}

\subsection{Giả thuyết nghiên cứu}

\subsubsection{Nhóm nhân tố về chính sách}

Theo Alinaitwe và cộng sự (2013), Subramani và cộng sự (2014) thì chính sách không ổn định là 01 trong 05 nhân tố gây ra sự trì hoãn và vượt dự toán trong các dự án xây dựng công. Có 07 yếu tố trong nhân tố chính sách ảnh hưởng đến rủi ro trong quá trình thực hiện dự án bao gồm: những thay đổi bất ngờ trong quản lý, thay đổi chính sách thuế, sự quốc hữu hóa, thay đổi chính phủ, chiến tranh và thiên tai, quyền sở hữu, và chi phí bồi thường. Enshassi và cộng sự (2009), Magamid và Bruland (2012) cũng có kết luận tương tự với nghiên cứu này.

Từ các nghiên cứu trên, tác giả rút ra các yếu tố chính sách đại diện cho nhóm nhân tố dẫn đến vượt dự toán là: (i) Các quy định về luật xây dựng, đầu tư; (ii) Chính sách tiền lương; (iii) Luật đấu thầu; (iv) Chính sách thuế.

H1: Độ ổn định của môi trường chính sách càng cao thì mưc độ vượt dư toán càng giảm

\subsubsection{Nhóm nhân tố về kinh tế}

Trong nghiên cứu của Alhomidan (2013), Radman, Menon, và Karim (2013) các điều kiện kinh tế như chính sách tiền tệ, tỷ lệ lạm phát, tỷ giá hối đoái không tốt dẫn đến ảnh hưởng khá mạnh đến chi phí dự án xây dựng. Khi lạm phát tăng, lãi suất cao và chi phí dự án cũng sẽ tăng lên. Một nhân tố khác là xu hướng lạm phát không ổn định do cầu vượt cung gây khan hiếm hàng hóa và dẫn đến giá cả leo thang. Tóm lại, các yếu tố đại diện về kinh tế dẫn đến vượt dự toán trong các dự án xây dựng công trình bao gồm: (1) Lạm phát; (2) Tỷ giá hối đoái; (3) Giá cả vật liệu; (4) Lãi suất; (5) Nguồn cung ứng nhân lực; và (6) Nguồn cung ứng vật tư.

\section{H2: Độ ổn định của môi trường kinh tế càng cao thì mức độ vượt dụ toán càng giảm}

\subsubsection{Nhóm nhân tố về môi truờng tụ nhiên - xã họi}

Theo Alhomidan (2013) và Enshassi và cộng sự (2009) các nhân tố dẫn đến vượt dự toán trong các dự án xây dựng của chính phủ bao gồm điều kiện địa chất phức tạp và thiên tai tự nhiên. Ngoài ra, điều kiện thời tiết thất thường cũng có mức độ ảnh hưởng khá lớn đối với tiến độ dự án (Sunjka \& Jacob, 2013).

Do đó, các nhân tố về môi trường sẽ bao gồm hai yếu tố đại diện đó là: (1) Thời tiết và (2) Địa chất.

Về nhóm yếu tố xã hội: Alghbari (2013) và Enshassi và cộng sự (2009) cho rằng các vướng mắc trong thực hiện kế hoạch dự án hoặc người dân xung quanh là yếu tố ảnh hưởng đến hoạt động triển khai dự án, dẫn đến trì trệ và vượt dự toán. Vì các dự án trải dài từ nơi này sang nơi khác nên cần rất nhiều mặt bằng từ người dân để xây dựng. Do đó, nếu mức chi phí đền bù, bồi thường cho người dân không thỏa đáng sẽ dẫn đến khó khăn, chậm trễ trong công tác giải 
phóng mặt bằng, gây phát sinh do yếu tố trượt giá, tăng chi phí cơ hội của dự án, vấn đề hiệu quả, và tiến độ của dự án bị ảnh hưởng (Luu, Nguyen, \& Nguyen, 2015).

Ngoài ra, sự phối hợp không đồng bộ giữa các cơ quan khi giải phóng mặt bằng cũng là một lực cản dẫn đến trì hoãn tiến độ và làm gia tăng chi phí. Căn cứ theo những nhận định trên, nhóm yếu tố về xã hội gồm hai yếu tố đại diện như sau: (1) Sự phối hợp không đồng bộ giữa các cơ quan; (2) Sự phản đối của người dân.

H3: Độ ổn định của môi truờng tụ nhiên - xã hội càng cao thì mức độ vuoọt dụ toán càng giảm

\subsubsection{Nhóm nhân tố về tư vấn}

Sự thay đổi thiết kế thường xuyên, lỗi thiếu sót trong tài liệu tư vấn, thiết kế kém và chậm trễ, đội ngũ tư vấn viên không đủ năng lực, ít kinh nghiệm là một trong những nhân tố gây đến việc vượt dự toán trong các dự án công (Larsen, Shen, Linhard, \& Brunoe, 2015; Radman et al., 2013). Trong khi đó, theo Odediran, Adeyinka, và Eghenure (2012) nguyên nhân lớn nhất dẫn đến việc vượt dự toán là do ước tính chi phí lúc đầu không chính xác.

Dựa trên các quan điểm đó, nhóm nhân tố về tư vấn dẫn đến vượt dự toán trong các dự án hạ tầng kỹ thuật gồm các yếu tố đại diện sau: (i) Năng lực của tư vấn viên kém; (ii) Chậm trễ tiến độ hoàn thành công việc; (iii) Ước tính tổng mức đầu tư không chính xác; (iv) Công tác khảo sát thiếu quan tâm chặt chẽ; và (v) Tài liệu tư vấn thiếu sót.

\section{H4: Năng lục của tư vấn càng cao thì mức độ vuợt dụ toán càng giảm}

\subsubsection{Nhón nhân tố về chủ đầu tur/ban quản lý}

Nhóm nhân tố này thể hiện năng lực của chủ đầu tư. Chủ đầu tư cần có một số khả năng như cung cấp thông tin về dự án kịp thời cho các bên tham gia dự án; am hiểu pháp luật về xây dựng; phối hợp thực hiện hợp đồng; giải quyết những khó khăn, phức tạp ... (Enshassi et al., 2009; Love et al., 2015). Ngoài ra, khuynh hướng lạc quan trong thẩm định dự án và dối trá là các nhân tố chính dẫn đến vượt dự toán trong các dự án trong ngành giao thông (Cantarelli, Molin, van Wee, \& Flyvbjerg, 2012).

Ngoài ra, Dang và Pheng (2015) phát hiện các nhân tố liên quan đến chủ đầu tư ảnh hưởng đến hoạt động yếu kém trong các dự án lớn tại Việt Nam là sự thiếu minh bạch và trách nhiệm giải trình trong việc phát triển cơ sở hạ tầng.

Trên cơ sở đó, tác giả đề xuất các yếu tố đại diện cho nhóm nhân tố liên quan đến chủ đầu tư dự án gồm: (1) Khả năng ra quyết định; (2) Năng lực ủy quyền cho cấp dưới; (3) Năng lực đàm phán; (4) Năng lực phối hợp với các bên tham gia dự án; (5) Kỹ năng quản lý dự án; (6) Kỹ năng giải quyết các khó khăn, vướng mắc phát sinh; (7) Khả năng thanh toán; (8) Tính minh bạch và trách nhiệm giải trình; (9) Quan liêu, và (10) Chậm trễ trong thu hồi đất.

\section{H5: Năng lục chủ đầu tư càng cao thì mức độ vượt dụ toán càng giảm}

\subsubsection{Nhân tố nhà thầu}

Chủ đầu tư, tư vấn và nhà thầu là 03 đối tác chính tham gia vào thực hiện dự án. Nhiệm vụ chính của nhà thầu là tập hợp và phân bổ các nguồn lực lao động, trang thiết bị máy móc và nguyên vật liệu đến dự án để hoàn thành hiệu quả tối đa về chi phí, thời gian và chất lượng (Larsen et al., 2015). Thực tế cho thấy quản lý và giám sát công trình, năng lực tài chính kém là một trong những vấn đề được quan tâm đầu tiên dẫn đến vượt dự toán trong các dự án xây dựng 
(Park, 2012). Ngoài ra, có các nguyên nhân khác dẫn đến việc vượt dự toán khá lớn là có phát sinh lỗi trong quá trình xây dựng.

Nhóm nhân tố về nhà thầu bao gồm các biến đại diện sau: (1) Quản lý và giám sát công trình kém; (2) Năng lực tài chính của nhà thầu chính; (3) Năng lực nhân sự của nhà thầu chính; (4) Máy móc, trang thiết bị của nhà thầu chính; (5) Xảy ra lỗi trong quá trình thi công; (6) Năng lực phối hợp giữa nhà thầu và chủ đầu tư.

H6: Năng lực của nhà thầu càng cao thì mức độ vượt dụ toán càng giảm

\subsection{Mô hìh nghiên cứu đề xuất}

Trên cơ sở 06 nhóm nhân tố dẫn đến vượt dự toán trong các dự án xây dựng hạ tầng kỹ thuật với nhân tố đại diện ở trên, mô hình nghiên cứu đề xuất như Hình 1 với sáu giả thuyết tương ứng:

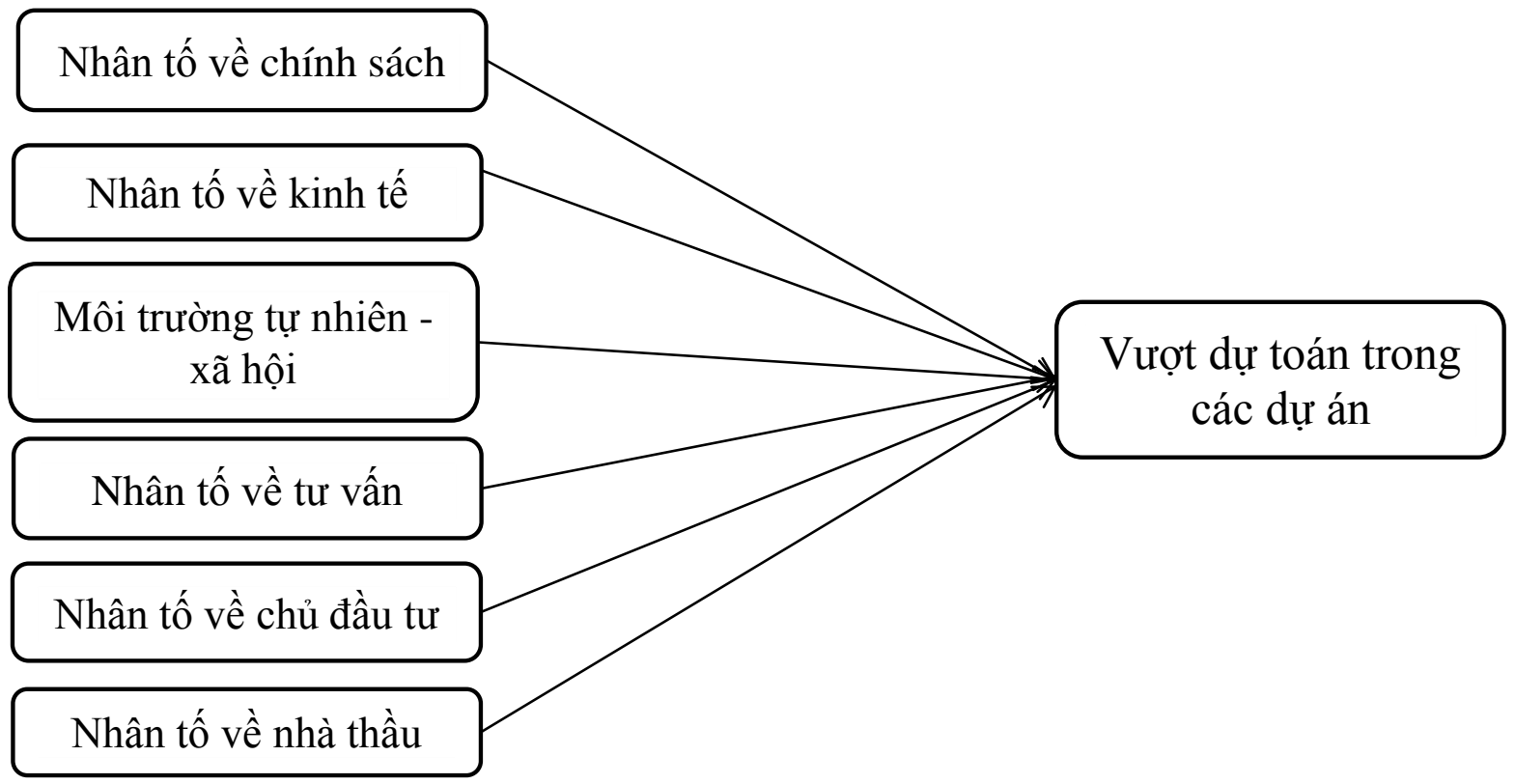

Hình 1. Mô hình nghiên cứu

\subsection{Phương pháp nghiên cứu}

Nghiên cứu được tiến hành thông qua nghiên cứu sơ bộ định tính và nghiên cứu chính thức định lượng. Bảng câu hỏi được phát trực tiếp đến cán bộ, công chức của các Sở Giao thông Vận tải, Khu quản lý giao thông đô thị, Ban quản lý dự án đầu tư cấp quận; các kỹ sư, chuyên viên tham gia thi công, xây dựng, giám sát công trình hạ tầng kỹ thuật trên địa bàn Thành phố.

Theo Hair, Black, Babin, và Anderson (2010), tỷ lệ quan sát/biến đo lường tối thiểu là $5: 1$. Nghiên cứu có 31 biến đo lường nên số mẫu dự kiến là $5 \times 31=155$. Thực tế tổng số lượng bảng hỏi phát ra là 200 phiếu. Kết quả thu về 195 bảng, trong có 184 bảng hợp lệ, đạt yêu cầu phân tích.

Thang đo dạng Likert 5 điểm được sử dụng trong bảng hỏi từ 1 (hoàn toàn không đồng ý) đến 5 (hoàn toàn đồng ý). Dữ liệu được tiến hành sàng lọc và xử lý dữ liệu bằng phần mềm SPSS thông quan các phân tích Cronbach's Alpha, nhân tố khám phá (EFA), phân tích tương quan và hồi quy đa biến. 


\section{Bảng 1}

Thang đo chính thức

\begin{tabular}{|c|c|c|c|c|c|}
\hline Biến quan sát & Mã biến & Min & Max & Mean & SD \\
\hline Chính sách & CS & & & 3.79 & .877 \\
\hline $\begin{array}{l}\text { Cơ chế Luật Đấu thầu, Luật Xây dựng không } \\
\text { rõ ràng }\end{array}$ & CS1 & 1 & 5 & 3.85 & .978 \\
\hline Chính sách tiền lương không ổn định & CS2 & 1 & 5 & 3.77 & .949 \\
\hline Chính sách thuế không ổn định & CS3 & 1 & 5 & 3.77 & 1.016 \\
\hline Kinh tế & KT & & & 3.63 & .082 \\
\hline Lạm phát vượt so với kế hoạch & KT1 & 2 & 5 & 3.64 & .900 \\
\hline Tỷ giá hối đoái vượt so với kế hoạch & KT2 & 2 & 5 & 3.64 & .888 \\
\hline $\begin{array}{l}\text { Giá cả nguyên vật liệu xây dựng vượt so với } \\
\text { kế hoạch }\end{array}$ & KT3 & 2 & 5 & 3.60 & .836 \\
\hline Lãi suất vay vốn vượt so với kế hoạch & KT4 & 2 & 5 & 3.72 & .865 \\
\hline Tiền lương nhân công tăng đột biến & KT5 & 2 & 5 & 3.57 & .859 \\
\hline Tụ̣ nhiên - xã hội & $\mathbf{T N}$ & 2 & 5 & 3.63 & .086 \\
\hline $\begin{array}{l}\text { Cơ quan khác phối hợp không đồng bộ khi thu } \\
\text { hồi, giải phóng mặt bằng }\end{array}$ & TN1 & 2 & 5 & 3.63 & .853 \\
\hline $\begin{array}{l}\text { Sự phản đối của người dân do việc bồi thường, } \\
\text { giải phóng mặt bằng không thỏa đáng }\end{array}$ & TN2 & 2 & 5 & 3.66 & .820 \\
\hline $\begin{array}{l}\text { Điều kiện về thời tiết/địa chất/thủy văn tại } \\
\text { công trường phức tạp hơn so với khảo sát }\end{array}$ & TN3 & 2 & 5 & 3.61 & .922 \\
\hline Tư vấn & TV & & & 3.62 & .082 \\
\hline Năng lực của Tư vấn viên kém & TV1 & 1 & 5 & 3.55 & .828 \\
\hline Chậm trễ tiến độ hoàn thành công việc & TV2 & 2 & 5 & 3.68 & .874 \\
\hline Ước tính tổng mức đầu tư không chính xác & TV3 & 2 & 5 & 3.62 & .841 \\
\hline Chủ đầu tư & CDT & & & 3.56 & 0.68 \\
\hline Khả năng ra quyết định kém & CDT1 & 2 & 5 & 3.62 & .772 \\
\hline Khả năng ủy quyền cho cấp dưới kém & CDT2 & 2 & 5 & 3.66 & .891 \\
\hline Khả năng đàm phán kém & CDT3 & 2 & 5 & 3.64 & .900 \\
\hline Khả năng phối hợp với các bên tham gia kém & CDT4 & 2 & 5 & 3.69 & .650 \\
\hline Khả năng quản lý dự án kém & CDT5 & 2 & 5 & 3.65 & .796 \\
\hline Khả năng giải quyết vấn đề phát sinh kém & CDT6 & 2 & 5 & 3.60 & .863 \\
\hline Thường xuyên thay đổi phạm vi dự án & CDT7 & 2 & 5 & 3.42 & .713 \\
\hline Thẩm định dự án không khách quan & CDT8 & 2 & 5 & 3.46 & .715 \\
\hline
\end{tabular}




\begin{tabular}{|c|c|c|c|c|c|}
\hline Biến quan sát & Mã biến & Min & $\operatorname{Max}$ & Mean & SD \\
\hline Chậm trễ khi thu hồi đất & CDT9 & 2 & 5 & 3.47 & .724 \\
\hline Tính minh bạch và trách nhiệm giải trình kém & CDT10 & 2 & 5 & 3.45 & .722 \\
\hline Nhà thầu & NT & & & 3.3 & .077 \\
\hline Quản lý và giám sát công trình kém & NT1 & 2 & 5 & 3.46 & .676 \\
\hline $\begin{array}{l}\text { Tài chính của nhà thầu chính không đủ đáp } \\
\text { ứng khi thi công }\end{array}$ & NT2 & 1 & 5 & 3.22 & .899 \\
\hline $\begin{array}{l}\text { Nhân lực của nhà thầu chính không đủ đáp } \\
\text { ứng khi thi công }\end{array}$ & NT3 & 2 & 5 & 3.34 & .659 \\
\hline Phương pháp xây dựng lạc hậu, không phù hợp & NT4 & 1 & 5 & 3.24 & .899 \\
\hline $\begin{array}{l}\text { Máy móc trang thiết bị không đủ đáp ứng theo } \\
\text { yêu cầu khi thi công }\end{array}$ & NT5 & 1 & 5 & 3.21 & .850 \\
\hline Lỗi trong quá trình thi công & NT6 & 1 & 5 & 3.27 & .856 \\
\hline $\begin{array}{l}\text { Năng lực phối hợp giữa nhà thầu và chủ đầu tư } \\
\text { kém }\end{array}$ & NT7 & 2 & 5 & 3.34 & .623 \\
\hline
\end{tabular}

Nguồn: Kết quả phân tích dữ liệu của tác giả

\section{Kết quả phân tích}

\subsection{Thống kê mô tả}

Loại hình dự án được thu thập nhiều nhất là các công trình giao thông gồm 78 công trình (chiếm tỷ lệ 37\%); công trình xây dựng dân dụng với 55 công trình (chiếm tỷ lệ $26 \%$ ); công trình công nghiệp với 40 công trình (chiếm tỷ lệ $19 \%$ ) và công trình thủy lợi chiếm tỷ lệ thấp nhất với $18 \%$, với 37 công trình. Hiện nay, chủ đầu tư trực tiếp quản lý dự án tại các công trình hạ tầng kỹ thuật tại Thành phố là phổ biến, các Ban quản lý dự án xây dựng của Ủy ban nhân dân quận, huyện, các khu quản lý giao thông đô thị trực thuộc Sở Giao thông vận tải và các Ban Quản lý dự án thuộc Ủy ban nhân dân Thành phố đảm nhận, với tỷ lệ gần $75 \%$. Đa số đối tượng được khảo sát là cán bộ kỹ thuật/chuyên viên với 80 người (tỷ lệ 43.48\%), kỹ sư là 74 người (tỷ lệ 40.22\%), Trưởng /Phó Ban quản lý dự án 11 người (tỷ lệ 5.98\%) và Thư ký dự án là 19 người (tỷ lệ $10.33 \%$ )

Tỷ lệ đối tượng khảo sát có kinh nghiệm quản lý dự án từ 05 - 10 năm chiếm tỷ lệ cao nhất với 40.22\% (74 người), tiếp theo là 03 - 05 năm với 56 người (tỷ lệ 30.43\%), dưới 03 năm kinh nghiệm là 22 người (tỷ lệ $11.96 \%$ ) và trên 10 năm kinh nghiệm là 32 người (tỷ lệ $17.39 \%$ ). Tuy nhiên, trên thực tế có sự khác biệt trong việc đánh giá vượt dự toán của nhóm đối tượng có số năm kinh nghiệm khác nhau và nhóm đối tượng tham gia các loại hình dự án khác nhau. Do vậy, tác giả sử dụng kiểm định ANOVA để tìm hiểu vấn đề này.

\subsection{Kiểm định thang đo}

Có 31 biến quan sát của sáu nhân tố được đưa vào phân tích. Các thang đo khái niệm nghiên cứu trước tiên được đánh giá bằng hệ số tin cậy Cronbach's Alpha. Kết quả kiểm tra Cronbach'Alpha cho thấy các hệ số này có giá trị từ 0.674 đến 0.842 đều lớn hơn 0.6 và đồng thời các biến quan sát của các thang đo đều có tương quan biến - tổng lớn hơn 0.3 . Do đó, có thể kết luận rằng các yếu tố được đề xuất đều có độ tin cậy cao. 


\subsubsection{Phân tích nhân tố khám phá EFA}

Tiếp theo, các biến quan sát tiếp tục được đưa vào phân tích nhân tố khám phá EFA. Kết quả phân tích EFA có ba biến bị loại vì chúng có hệ số tải nhân tố nhỏ hơn 0.5 (các biến CDT5, CDT7, NT6). Các biến còn lại đều đạt yêu cầu. Sau khi phân tích EFA có sáu yếu tố được trích ra từ 28 biến quan sát (Bảng 2). Kết quả phân tích về EFA cho thấy các khái niệm nghiên cứu trích được 62.934\% phương sai các biến quan sát tại Eigenvalue là 1.036, hệ số KMO là 0.817 . Kết quả cho thấy các thang đo khái niệm sử dụng trong nghiên cứu này là thang đo đơn hướng và đạt giá trị hội tụ. Tiếp theo nghiên cứu thực hiện kiểm tra tương quan và phân tích hồi quy đa biến để kiểm định các giả thuyết nghiên cứu.

\section{Bảng 2}

Kết quả phân tích nhân tố

\begin{tabular}{|c|c|c|c|c|c|c|}
\hline \multirow{2}{*}{ Biến } & \multicolumn{5}{|c|}{ Nhân tố } & \multirow[b]{2}{*}{ NT } \\
\hline & CDT & KT & CS & TN & TV & \\
\hline CDT1 & .883 & & & & & \\
\hline CDT2 & .871 & & & & & \\
\hline CDT4 & .863 & & & & & \\
\hline CDT6 & .859 & & & & & \\
\hline CDT3 & .824 & & & & & \\
\hline CDT8 & .785 & & & & & \\
\hline CDT9 & .757 & & & & & \\
\hline CDT10 & .749 & & & & & \\
\hline KT2 & & .791 & & & & \\
\hline KT3 & & .782 & & & & \\
\hline KT5 & & .741 & & & & \\
\hline KT1 & & .714 & & & & \\
\hline KT4 & & .705 & & & & \\
\hline CS3 & & & .852 & & & \\
\hline CS1 & & & .842 & & & \\
\hline CS2 & & & .813 & & & \\
\hline TN1 & & & & .802 & & \\
\hline TN2 & & & & .768 & & \\
\hline TN3 & & & & .745 & & \\
\hline TV2 & & & & & . 777 & \\
\hline TV1 & & & & & .774 & \\
\hline TV3 & & & & & .686 & \\
\hline
\end{tabular}




\begin{tabular}{|c|c|c|c|c|c|c|}
\hline \multirow{2}{*}{ Biến } & \multicolumn{5}{|c|}{ Nhân tố } & \multirow[b]{2}{*}{ NT } \\
\hline & CDT & KT & CS & $\mathbf{T N}$ & TV & \\
\hline NT1 & & & & & & .847 \\
\hline NT3 & & & & & & .845 \\
\hline NT4 & & & & & & .747 \\
\hline NT7 & & & & & & .695 \\
\hline NT5 & & & & & & .690 \\
\hline NT2 & & & & & & .634 \\
\hline $\begin{array}{c}\text { Cronbach's } \\
\text { Alpha }\end{array}$ & .842 & .674 & .734 & .747 & .778 & .785 \\
\hline $\begin{array}{l}\text { Phương sai } \\
\text { trích lũy tiến } \\
\qquad \%)\end{array}$ & 29.348 & 41.610 & 51.239 & 59.734 & 62.934 & 65.831 \\
\hline $\begin{array}{c}\text { Hệ số } \\
\text { Eigenvalue }\end{array}$ & 4.989 & 2.085 & 1.637 & 1.444 & 1.265 & 1.036 \\
\hline \multicolumn{7}{|c|}{ Hệ số KMO = 0.817} \\
\hline Kiểm định $\mathrm{Ba}$ & t's Test & ó Sig. = & & & & \\
\hline
\end{tabular}

Nguồn: Kết quả phân tích dữ liệu của tác giả

\subsubsection{Phân tích tương quan và hồi quy đa biến}

Sau khi thực hiện phân tích EFA, có sáu yếu tố được trích ra từ 28 biến quan sát. Tác giả tiến hành tạo các biến đại diện bao gồm: Chính Sách (CS), Kinh Tế (KT); Vượt Dự Toán (VDT); Tự Nhiên - Xã Hội (TN); Tư Vấn (TV); Chủ Đầu Tư (CDT) và Nhà Thầu (NT). Bảng 3 cho thấy các yếu tố độc lập có hệ số tương quan dương từ 0.301 đến 0.602 với yếu tố phụ thuộc. Trong đó nhân tố Chủ Đầu Tư $(\mathrm{CDT})$ và nhân tố Nhà thầu $(\mathrm{NT})$ có sự tương quan mạnh đến biến phụ thuộc.

\section{Bảng 3}

Kết quả kiểm định tương quan giữa các biến

\begin{tabular}{|c|c|c|c|c|c|c|c|}
\hline & VDT & $\mathrm{CS}$ & KT & TN & TV & CDT & NT \\
\hline VDT & 1 & $.301^{*}$ & $.412^{* *}$ & $.401^{* *}$ & $.490^{* *}$ & $.612^{* *}$ & $.543^{* *}$ \\
\hline CS & & 1 & $.240^{* *}$ & $.199^{* *}$ & $.272^{* *}$ & $.221^{* *}$ & $.385^{* *}$ \\
\hline KT & & & 1 & $.323^{* *}$ & $.188^{* *}$ & $.269^{* *}$ & $.270^{* * *}$ \\
\hline TN & & & & 1 & $.182^{* *}$ & $.333^{* *}$ & $.232^{* *}$ \\
\hline TV & & & & & 1 & $.197^{* *}$ & $.172^{* *}$ \\
\hline CDT & & & & & & 1 & $.203^{* *}$ \\
\hline NT & & & & & & & 1 \\
\hline
\end{tabular}

Nguồn: Tác giả tổng hợp từ EVIEWS 
Tiếp theo, nghiên cứu tiến hành phân tích hồi quy để kiểm định các giả thuyết nghiên cứu. Bảng 4 cho thấy hệ số R2 hiệu chỉnh $=0.667$ có nghĩa là $66.7 \%$ mức biến thiên của biến phụ thuộc vượt dự toán của dự án được giải thích bởi sáu yếu tố độc lập. Kết quả hồi quy cho thấy giá trị Sig. của kiểm định $\mathrm{F}=0.000$. Ngoài ra, hiện tượng đa cộng tuyến cũng được kiểm tra thông qua hệ số VIF và được xác nhận không có hiện tượng đa cộng tuyến.

Kết quả nghiên cứu cho thấy nhân tố Chủ Đầu Tư $(C D T)$ có hệ số cao nhất $(\beta=0.371)$ nên tác động mạnh nhất đến khả năng vượt dự toán của dự án; tiếp theo là nhân tố Nhà Thầu (NT) với hệ số là 0.279 ; tiếp theo là nhân tố Tư vấn với hệ số 0.206 , kế đến là nhân tố Kinh tế, nhân tố Môi trường tự nhiên - xã hội, nhân tố Chính sách.

Phương trình hồi quy được trình bày như sau:

$$
\mathrm{VDT}=0.279 * \mathrm{NT}+0.371 * \mathrm{CDT}+0.143 * \mathrm{TN}+0.206 * \mathrm{TV}+0.127 * \mathrm{CS}+0.185 * \mathrm{KT}
$$

Như vậy, các nhân tố tác động đến khả năng vượt dự toán của dự án được sắp xếp theo thứ tự tăng dần như sau Chính sách; Môi trường tự nhiên - xã hội; Kinh tế; Tư vấn; Nhà thầu; Chủ đầu tư.

\section{Bảng 4}

Kết quả phân tích hồi quy

\begin{tabular}{|c|c|c|c|c|c|c|c|}
\hline \multirow{2}{*}{ Mô hình } & \multicolumn{2}{|c|}{$\begin{array}{c}\text { Hệ số hồi quy chưa } \\
\text { chuẩn hóa }\end{array}$} & \multirow{2}{*}{$\begin{array}{c}\text { Hệ số hồi quy } \\
\text { chuẩn hóa }\end{array}$} & \multirow{2}{*}{$\mathbf{t}$} & \multirow{2}{*}{ Sig. } & \multirow{2}{*}{$\begin{array}{c}\text { Hệ số } \\
\text { Tolerance }\end{array}$} & \multirow{2}{*}{$\begin{array}{l}\text { Hệ số } \\
\text { V.I.F }\end{array}$} \\
\hline & Giá trị B & Sai số chuẩn & & & & & \\
\hline Hằng số & .262 & .169 & & -1.549 & .123 & & \\
\hline NT & .226 & .035 & .279 & 6.453 & .000 & .786 & 1.272 \\
\hline $\mathrm{CDT}$ & .283 & .032 & .371 & 8.749 & .000 & .820 & 1.220 \\
\hline $\mathrm{TN}$ & .110 & .033 & .143 & 3.334 & .001 & .802 & 1.246 \\
\hline $\mathrm{TV}$ & .172 & .036 & .206 & 4.826 & .000 & .811 & 1.233 \\
\hline $\mathrm{CS}$ & .106 & .035 & .127 & 3.030 & .003 & .833 & 1.201 \\
\hline KT & .119 & .026 & .185 & 4.557 & .000 & .891 & 1.122 \\
\hline
\end{tabular}

Hệ số R2 = 0.676

Hệ số R2 hiệu chỉnh $=0.667$

Hệ số Durbin - Watson $=1.946$

Kiểm định $\mathrm{F}$ với giá trị Sig. $=0.000$

Nguồn: Kết quả phân tích dữ liệu của tác giả

\subsubsection{Kiểm định ANOVA}

Nghiên cứu thực hiện kiểm định ANOVA nhằm tìm hiểu sự khác biệt trong việc đánh giá vượt dự toán của nhóm đối tượng có số năm kinh nghiệm khác nhau và nhóm đối tượng tham gia các loại hình dự án khác nhau.

Nhóm đối tương có số năm kinh nghiệm khác nhau 


\section{Bảng 5}

Kiểm định ANOVA theo kinh nghiệm công tác

\begin{tabular}{lccccc}
\hline \multicolumn{1}{c}{ Levene Statistic } & df1 & df2 & \multicolumn{2}{c}{ Sig. } \\
\hline \multicolumn{1}{c}{3.382} & 3 & & 180 & \multicolumn{2}{c}{.251} \\
\hline & $\begin{array}{c}\text { Tổng bình } \\
\text { phương }\end{array}$ & df & $\begin{array}{c}\text { Trung bình } \\
\text { bình phương }\end{array}$ & F & Sig. \\
\hline Giữa các nhóm & .040 & 3 & .013 & 2.163 & .095 \\
Trong mỗi nhóm & .901 & 180 & .006 & & \\
Tổng & .941 & 183 & & & \\
\hline
\end{tabular}

Nguồn: Kết quả phân tích dữ liệu của tác giả

Kiểm định Levene cho giá trị Sig. $=0.251>0.05$, do đó phương sai nhóm số năm kinh nghiệm là như nhau. Kết quả kiểm định ANOVA cho thấy giá trị Sig. $=0.095>0.05$, vậy không có sự khác biệt trong việc đánh giá vượt dự toán của những người có kinh nghiệm khác nhau.

Nhóm đối tuợng tham gia các loại hình dụ án khác nhau

\section{Bảng 6}

Kiểm định ANOVA theo các loại hình dự án

\begin{tabular}{cccccc}
\hline Levene Statistic & df1 & df2 & \multicolumn{2}{c}{ Sig. } \\
\hline 0.619 & 3 & & 180 & \multicolumn{2}{c}{.604} \\
\hline & & & & & \\
\hline & $\begin{array}{c}\text { Tổng bình } \\
\text { phương }\end{array}$ & df & $\begin{array}{c}\text { Trung bình } \\
\text { bình phương }\end{array}$ & F & Sig. \\
\hline Giữa các nhóm & .004 & 3 & .001 & 1.94 & .92 \\
Trong mỗi nhóm & .937 & 180 & .006 & & \\
Tổng & .941 & 183 & & & \\
\hline
\end{tabular}

Nguồn: Kết quả phân tích dữ liệu của tác giả

Kiểm định Levene cho giá trị Sig. $=0.604>0.05$, do đó phương sai nhóm đối tương tham gia các loại hình dự án là như nhau. Kết quả kiểm định ANOVA cho thấy giá trị Sig. $=0.92$ $>0.05$, vậy không có sự khác biệt trong việc đánh giá vượt dự toán của những người tham gia các loại hình dự án khác nhau.

\subsubsection{Thảo luận kết quả và hàm ý quản trị}

Kết quả từ Bảng 4 cho thấy tất cả các giả thuyết đề xuất đều được chấp nhận. Nghĩa là tất cả các yếu tố Chính sách, Kinh tế, Môi trường tự nhiên - xã hội, Chủ đầu tư, Tư vấn, Nhà thầu đều tác động đến việc vượt dự toán của dự án.

Năng lực của Chủ Đầu Tư (CDT) có tác động mạnh nhất lên khả năng vượt dự toán của dự án với hệ số $\beta=0.371$. Điều này cho thấy năng lực của chủ đầu tư là một vấn đề quan trọng 
và có tính quyết định đến khả năng vượt dự toán của dự án. Do đó, cần nâng cao năng lực chuyên môn của chủ đầu tư, ban quản lý dự án chuyên ngành nhằm phù hợp với xu hướng phát triển. Cán bộ, công chức cần thường xuyên được cập nhật các quy định pháp luật mới. Ngoài ra, chủ đầu tư phải dự trù nhiều kế hoạch, phương án nhằm xử lý, khắc phục các tình huống bất lợi trong công tác đấu thầu.

Tinh thần trách nhiệm của chủ đầu tư cũng phải được xem trọng. Việc phân công trách nhiệm của các nhân viên trong dự án phải được rõ ràng, minh bạch; những hoạt động mà họ cần thực hiện cùng với việc nhà quản lý có kỹ năng quản lý, khả năng động viên sẽ làm gắn kết các thành viên, đẩy nhanh tiến độ thực hiện các dự án.

Tiếp theo, nhân tố Nhà Thầu (NT) có tác động mạnh thứ hai lên khả năng vượt dự toán của dự án với hệ số $\beta=0.279$. Do đó, khi chọn nhà thầu phải chú ý đến những nhà thầu có năng lực kinh nghiệm, chuyên môn nghiệp vụ cao, năng lực tài chính vững vàng. Nhà thầu phải có đạo đức nghề nghiệp, đã thực hiện tốt nhiều dự án với quy mô, tính chất tương tự, đảm bảo an toàn tuyệt đối khi thi công. Để làm được việc này thì ngay từ các công tác ban đầu khi lựa chọn nhà thầu cần có công tác thẩm định chặt chẽ trong việc chọn nhà thầu, đặc biệt trong quá trình đấu thầu cần tránh tình trạng lựa chọn nhà thầu giá rẻ nhưng năng lực thi công hạn chế, không đảm bảo chất lượng.

Tiếp theo, nhân tố Tư vấn có tác động mạnh thứ ba lên khả năng vượt dự toán. Chủ đầu tư cần thuê tư vấn đủ năng lực để thực hiện các công việc theo quy định làm cơ sở pháp lý cho các quyết định phê duyệt của Chủ đầu tư.

Đối với nhóm yếu tố về tự nhiên - xã hội: thực tế hiện nay công tác đền bù giải phóng mặt bằng là yếu tố trở ngại đối với tiến độ hoàn thành dự án, dẫn đến dự án vượt dự toán. Điều này có nguyên nhân là do giá đền bù hỗ trợ tại thời điểm xây dựng và thời điểm tiến hành bồi thường, giải phóng mặt bằng là khác nhau, có độ chênh lệch. Vì vậy, khi triển khai xây dựng, giá đền bù phải phù hợp, sát với giá thị trường để tránh việc khiếu kiện của người dân. Bên cạnh đó, cần đẩy mạnh tuyên truyền để tạo sự đồng thuận cho người dân. Trong quá trình triển khai dự án, rất cần sự phối hợp giữa các cơ quan ban ngành để phối hợp, trao đổi thông tin nhanh và chính xác. Ngoài ra, các điều kiện về tự nhiên như: Thời tiết, địa chất, thủy văn cần phải được quan tâm, tránh trường hợp khảo sát không đạt gây hậu quả nghiêm trọng.

Bên cạnh đó, cần phải dự tính trước giá nhân công, nguyên vật liệu cũng như tỷ lệ lạm phát, lãi vay trong suốt quá trình thi công. Tính đúng và tính đủ mang yếu tố quyết định thành công của dự án trong tình hình hiện nay.

\section{Kết luận}

Nghiên cứu phân tích các yếu tố ảnh hưởng đến việc vượt dự toán trong các dự án xây dựng hạ tầng kỹ thuật tại Thành phố Hồ Chí Minh. Kết quả phân tích hồi quy cho thấy các nhân tố tác động đến khả năng vượt dự toán của dự án được sắp xếp theo thứ tự giảm dần như sau: Chủ đầu tư; Nhà thầu; Tư vấn; Kinh tế; Môi trường tự nhiên - xã hội; Chính sách. Kết quả nghiên cứu này phù hợp với các nghiên cứu của Durdyev và cộng sự (2017); Johnson và Babu (2020); Ilyas và cộng sự (2019); và Prasad và cộng sự (2019).

Nghiên cứu này không tránh khỏi một số hạn chế. Một là, nghiên cứu này chỉ tập trung thực hiện tại Thành phố Hồ Chí Minh và chỉ giới hạn trong một kích thước mẫu chưa cao. Nghiên cứu có thể sẽ mang lại kết quả tốt hơn nếu như được thực hiện trên một khu vực rộng lớn hơn như ở các thành phố khác của Việt Nam. Ngoài ra, nghiên cứu chỉ thực hiện khảo sát các dự 
án chung mà không hỏi theo từng dự án, tác giả đề xuất hướng nghiên cứu tiếp thoe nên tiến hành khảo sát đối với từng dự án cụ thể. Nghiên cứu trong tương lai có thể mở rộng đến các yếu tố này để tăng sự toàn diện về vấn đề này.

\section{Tài liệu tham khảo}

Alghbari, W. (2013). The significant factors causing delay of building construction projects in Malaysia. Journal of Engineering, Construction and Architectural Management, 14(2), 192-206.

Alhomidan, A. (2013). Factors affectingf cost overrun in road construction projects in Saudi Arabia. International Journal of Civil \& Environment Engineering, 13(3), 1-4.

Ali, A. S., \& Kamaruzzaman, S. N. (2010). Cost performance for building construction projects in Klang Valley. Journal of Building Performance, 1(1), 110-118.

Alinaitwe, H., Apolot, R., \& Tindiwensi, D. (2013). Investigation into the causes of delays and cost overruns in Uganda's public sector construction projects. Journal of Construction in Developing Countries, 18(2), 33-47.

Khalil, M. I. A., \& Ghafly, M. A. A. (1999). Important causes of delay in public utility projects in Saudi Arabia. International Journal of Project Management, 17(2), 647-655.

Andric, J. M., Mahamadu, A. M., Wang, J., Zou, P. X. W., \& Zhong, R. (2019). The cost performance and causes of overruns in infrastructure developments in Asia. Journal of Civil Engineering and Management, 25(3), 203-214.

Bari, N. A. A., Yusuff, R., Ismail, N., Jaapar, A., \& Ahmad, N. (2012). Factors influencing the construction cost of Industrialized Building System (IBS) projects. Procedia - Social and Behavioral Sciences, 35, 689-696.

Cantarelli, C. C., Molin, E. J. E., Wee, B. V., \& Flyvbjerg, B. (2012). Characteristics of cost overruns for Dutch transport infrastructure projects and the importance of the decision to build and project phases. Transport Policy, 22, 49-56.

Cao, T. H., \& Swierczek, F. W. (2010). Critical success factors in project management: Implication from Vietnam. Asia Pacific Business Review, 16(4), 567-589.

Dang, G. T. H., \& Pheng, L. S. (2015). Critical factors affecting the efficient use of public investments in infrastructure in Vietnam. Journal of Infrastructure Systems, 21(3), Article 05014007.

Datta, B. (2002). Management of infrastructure projects in urban local bodies: Case study of Kanpur development authority. In India infrastructure report (pp. 207-221). New Delhi, India: Oxford University Press.

Durdyev, S., Omarov, M., Ismail, S., \& Lim, M. (2017). Significant contributors to cost overruns in construction projects in Cambodia. Cogent Engineering, 4(1),1-10.

Enshassi, A., Mohamed, S., \& Abushaban, S. (2009). Factors affecting the performance of construction projects in the Gaza Strip. Journal of Civil Engineering and Management, 15(3), 269-280.

Hair, J. F., Black, W. C., Babin, B. J., \& Anderson, R. E. (2010). Multivariate data analysis. Englewood Cliffs, NJ: Prentice Hall. 
Honrao, Y., \& Desai, D. (2015). Study of delay in execution of infrastructure projects-highway construction. International Journal of Scientific and Research Publications, 5(6), 1-8.

Ilyas, M., Li, J., \& Ulah, I. (2019). Assessment of critical factors responsible for cost and time overruns in Pre construction planning phase of construction projects. Civil and Environmental Research, 11(12), 58-65.

Johnson, R. M., \& Babu, R. I. I. (2020). Time and cost overruns in the UAE construction industry: A critical analysis. International Journal of Construction Management, 20(5), 402-411.

Larsen, J. K., Shen, G. Q. P., Lindhard, S. M., \& Brunoe, T. D. (2015). Factors affecting schedule delay, cost overrun, and quality level in public construction projects. Journal of Management in Engineering, 32(1), Article 04015032.

Le, L. H., Lee, Y. D., \& Lee, J. Y. (2008). Delay and cost overrun in Vietnam large construction project: A comparison with other selected countries. KSCE Journal of Civil Engineering, 12(6), 367-377.

Love, P. E. D., Smith, J., Simpson, I., Regan, M., \& Olatunji, O. (2015). Understanding the landscape of overruns in transport infrastructure projects. Environment and Planning: Planning and Design, 42(3), 490-509.

Luu, V. T., Nguyen, S. M., \& Nguyen, V. T., (2015). A conceptual midel of delay factors affecting government construction projects. ARPN Journal of Science and Technology, 5(2), 92-100.

Magamid, I., \& Bruland, A. (2012). Cost deviation in road construction project: The case of Palestine. Australian Journal of Construction Economics and Building, 12(1), 58-71.

Mwelu, N., Davis, P., Ke, Y., Watundu, S., \& Jefferies, M. (2019). Success factors for implementing Uganda's public road construction projects. International Journal of Construction Management, 21, 598-614.

Nguyen, T. T. M. (2009). Các nhân tố ảnh hưởng đến biến động chi phí dự án xây dựng [Factors affecting fluctuations in construction project costs]. Sciences \& Techonology Development, 12(1), 104-117.

Odediran, S. J., Adeyinka, B. F., \& Eghenure, F. O. (2012). A study of factors influencing overruns of construction prjoects in Nigeria. Jornal of Architcture, Planning \& Construction Management, 2(2), 20-36.

Olawale, Y., \& Sun, M. (2010). Cost and time control of construction projects: Inhibiting factors and mitigating measures in practice. Construction Management and Economics, 28(5), 509-526.

Park, Y. I (2012). Causes of cost overruns in transport infrastructure projects in Asia: Their significance and relationship with project size. Built Environment Project and Asset Management, 2(2), 195-216.

Prasad, K., Vasugi, V., Venkatesan, R., \& Bhat, N. S. (2019). Critical causes of time overrun in Indian construction projects and mitigation measures. International Journal of Construction Education and Research, 15(3), 216-238.

Radman, I. A., Memon, A. H., \& Karim, A. T. A. (2013). Significant factors causing cost overruns in large projects in Malaysia. Journal of Applied Sciences, 13(2), 286-293. 
Subramani, T., Sruthi, P. S., \& Kavitha, M. (2014). Causes and cost of overrun in construction. Journal of Engineering, 4(6), 1-7.

Sunjka, B. P., \& Jacob, U. (2013). Significant causes and effects of project delays in the Niger delta region, Nigeria. SAIIE25 Proceedings, 9th - 11th of July 2013, Stellenbosch, South Africa, 1-13. Retrieved May 10, 2020, from https://conferences.sun.ac.za/ index.php/saiie25/SAIIE25/paper/viewFile/641/228

Trinh, T. A (2014). Các yếu tố gây chậm trễ trong các dự án giao thông sử dụng vốn ngân sách nhà nước tại các tỉnh phía nam [Factors causing delays in transport projects funded by the state budget in the southern provinces]. Tạp chi Khoa học Thuong mại, 72(8), 17-23. 